\title{
Future directions in the Internet-cloud computing and beyond
}

\section{Letter from the Editors-in-Chief}

\author{
Gordon Blair · Fabio Kon
}

Published online: 27 October 2011

(C) The Brazilian Computer Society 2011

We would like to welcome you to the volume 2, number 3 of the Journal of Internet Services and Applications. In this issue, we conclude the special issue on cloud computing with four papers as introduced by the guest editorial by Dilma Da Silva, Dongyan Xu and Dan Reed (see guest editorial for details). Please also refer to part 1 of this special issue last time round. We would like to thank the three guest editors for putting together this impressive array of papers on what is a very important topic for the future of the Internet. It has been a pleasure working with you.

This issue also includes a paper by Hiroshi Fujinoki and Andrew Hauck featuring an "Analysis on the Current and Future Internet Structure regarding Multi-honed Multi-path Routing”. This paper raises important questions about the structure of the Internet in terms of improving reliability of message traffic.
In writing this editorial, we should also pause and remember the sad passing of Steve Jobs. Many of us have worked in mobile computing motivated by the potential of mobile devices to change business and society. Our efforts shrink in comparison to the contributions of Steve Jobs who has done more than anyone to bring mobile computing to the masses and to transform the way we work and play. He will be sadly missed by the Computing community and also by people all over the world who have benefited from his work and vision.

As Editors-in-Chief, we are delighted by the quality and quantity of papers we are attracting to the journal on a range of really central topics about future directions in Internet services and applications.

Editors-in-Chief

G. Blair

Lancaster University, Lancaster, UK

e-mail: gordon@comp.lancs.ac.uk

F. Kon ( $₫)$

University of São Paulo, São Paulo, Brazil

e-mail: fabio.kon@ime.usp.br 